\title{
Promoting effects of IL-23 on myocardial ischemia and reperfusion are associated with increased expression of IL-17A and upregulation of the JAK2-STAT3 signaling pathway
}

\author{
YANXI LIAO ${ }^{1,2}$, XIAORONG HU ${ }^{2}$, XIN GUO $^{2}$, BOFANG ZHANG ${ }^{2}$, WEIPAN XU ${ }^{3}$ and HONG JIANG ${ }^{2}$ \\ ${ }^{1}$ Department of Cardiology, Central Hospital of Wuhan, Wuhan, Hubei 430014; ${ }^{2}$ Department of Cardiology, \\ Renmin Hospital of Wuhan University, Cardiovascular Research Institute of Wuhan University, Wuhan, \\ Hubei 430060; ${ }^{3}$ Department of Cardiology, Huangshi Central Hospital, Affiliated Hospital of Hubei \\ Polytechnic University, Edong Healthcare Group, Huangshi, Hubei 435002, P.R. China
}

Received July 3, 2016; Accepted May 2, 2017

DOI: $10.3892 / \mathrm{mmr} .2017 .7771$

\begin{abstract}
Interleukin (IL)-23, as a novel pro-inflammatory cytokine, is important in several inflammatory diseases, including myocardial ischemia and reperfusion (I/R) injury, however, the underlying mechanism remains to be elucidated. The present study was designed to investigate the specific role of IL-23 in myocardial I/R injury, and whether the Janus kinase 2/signal transducer and activator of transcription 3 (JAK2-STAT3) signaling pathway, one of the important downstream signaling pathways of IL-23, and the IL-17A downstream pro-inflammatory cytokine, were involved. Anesthetized rats underwent different treatments with adenovirus (Ad) vectors (Ad-GFP, Ad-IL-23, Anti-IL-23 or Ad-IL-23+AG490) and were then subjected to ischemia for $30 \mathrm{~min}$ prior to $4 \mathrm{~h}$ reperfusion. The effects of the upregulation and downregulation of IL-23 on myocardial injury, inflammatory responses in myocardial tissue, and myocardial apoptosis were measured accordingly. In addition, the levels of phosphorylated (P-)JAK2 and P-STAT3 were measured to assess the activity of the JAK2-STAT3 signaling pathway. The results demonstrated that there was an increased expression of IL-23 in the myocardial tissue exposed to myocardial I/R injury $(\mathrm{P}<0.05)$. The upregulation of IL-23 significantly increased the infarct size and the expression levels of lactate dehydrogenase and creatine kinase $(\mathrm{P}<0.05)$. The upregulation of IL-23 significantly increased inflammatory responses, as reflected by the high expression levels of IL-17A, IL-6, tumor necrosis
\end{abstract}

Correspondence to: Professor Hong Jiang, Department of Cardiology, Renmin Hospital of Wuhan University, Cardiovascular Research Institute of Wuhan University, 238 Jiefang Road, Wuhan, Hubei 430060, P.R. China

E-mail: jianghwurm@163.com

Key words: interleukin-23, myocardial ischemia and reperfusion injury, interleukin-17A, Janus kinase 2/signal transducer and activator of transcription 3 signaling pathway factor- $\alpha$ in the myocardial tissues $(\mathrm{P}<0.05)$. Furthermore, the upregulation of IL-23 significantly facilitated the decrease in the B-cell lymphoma 2 (Bcl-2)/Bcl-2-associated X protein ratio, and the increases in the myocardial apoptotic index and expression of caspase-3 induced by myocardial I/R $(\mathrm{P}<0.05)$. IL-23 also activated the JAK2-STAT3 signaling pathway, upregulating the expression levels of P-JAK2 and P-STAT3 in the myocardial tissues $(\mathrm{P}<0.05)$. Treatment with AG490, an inhibitor of JAK2-STAT3, partially attenuated the pro-inflammatory and pro-apoptotic effects of IL-23 $(\mathrm{P}<0.05)$. The results of the present study suggested that IL-23 aggravated myocardial I/R injury by promoting inflammatory responses and myocardial apoptosis, which may be associated with high expression levels of IL-17A and upregulation of the JAK2-STAT3 signaling pathway.

\section{Introduction}

Myocardial infarction is a serious disease, which contributes to high mortality rates in modern society. Myocardial reperfusion therapies, including percutaneous coronary intervention, thrombolytic therapy and coronary artery bypass grafts, have been regarded as the most effective approaches for rescuing ischemic myocardial tissue. However, regardless of the type of effective reperfusion therapy used for myocardial infarction, reperfusion itself can cause further myocardial injury, which can even attenuate the therapeutic benefit (1). Myocardial I/R can induce local myocardial inflammation, including promoting the release of various cytokines, including interleukin (IL)-17A, tumor necrosis factor- $\alpha$ (TNF- $\alpha$ ) and IL-6, and promoting the activation of inflammatory cells, including neutrophils, which is one of the crucial pathophysiological processes in myocardial I/R injury (2-4). Apoptosis is another pathological result of myocardial I/R, which can result in reversible or irreversible damage of myocardial tissue, accompanied with the inflammatory processes mentioned above (5).

IL-23, as a newly-identified member of the IL-12 family, has attracted increased attention (6). IL-23, predominantly produced by activated macrophages and dendritic cells, is a heterodimeric cytokine composed of IL-23p19 and 
IL-12/IL-23p40 subunits (7). Previous studies have confirmed that IL-23, as a pro-inflammatory cytokine, is critical in infections, autoimmune diseases, tumors and inflammatory diseases, including myocardial I/R injury, by promoting the expression of inflammatory cytokines and inflammatory responses (8-11). IL-17A, expressed at high levels in myocardial I/R injury, has been described as a downstream pro-inflammatory cytokine. The inhibition of IL-17A release can reduce myocardial I/R injury and improve cardiac function (12). Studies have also indicated that IL-23 can regulate the expression of IL-17A $(8,11)$. The present study attempted to test the hypothesis that IL-23 aggravates myocardial I/R injury by promoting inflammatory responses and myocardial apoptosis, which may be associated with the high expression of IL-17A and upregulation of the Janus kinase 2/signal transducers and activators of transcription 3 (JAK2-STAT3) signaling pathway.

\section{Materials and methods}

Construction of adenovirus (Ad) vectors. IL-23 and empty plasmid Ads (termed Ad-IL-23 and Ad-GFP) were constructed by cloning the IL-23 cDNA or empty plasmid. The recombinant viruses were then amplified in HEK 293 cells (American Type Culture Collection, Manassas, VA, USA) by transfection and finally purified using an Adeno- $\mathrm{X}^{\mathrm{TM}}$ purification kit (Microbix Biosystems, Toronto, ON, Canada) in order to reach the titer of $10^{11} \mathrm{pfu} / \mathrm{ml}$.

Animal preparation and experimental design. All experimental protocols conformed to the Guideline for the Care and Use of Laboratory Animals published by the US National Institutes of Health (NIH Publication, revised 1996) (13) and were approved by the Renmin Hospital of Wuhan University Animal Care and Use Committee (Wuhan, China). Male Sprague-Dawley rats (200-250 g) were supplied by the Experimental Animal Center of Vital River Laboratories (Beijing, China) and randomly assigned into the following six treatment groups: Group 1, sham-operated control $(\mathrm{SO} ; \mathrm{n}=10)$ rats subjected to surgery without myocardial ischemia; group $2, \mathrm{I} / \mathrm{R}(\mathrm{n}=10)$ rats subjected to occlusion of the left anterior descending coronary artery (LAD) for $30 \mathrm{~min}$, followed by reperfusion for $4 \mathrm{~h}$; group 3, Ad-GFP+I/R ( $\mathrm{n}=6)$ rats treated with Ad-GFP $\left(10^{11} \mathrm{pfu} / \mathrm{ml}, 100 \mu \mathrm{l}\right.$ per rat, intramyocardially) for $72 \mathrm{~h}$ prior to LAD occlusion; group 4, Ad-IL-23+I/R $(\mathrm{n}=6)$ rats treated with Ad-IL-23 (10 $10^{11} \mathrm{pfu} / \mathrm{ml}, 100 \mu \mathrm{l}$ per rat, intramyocardially) for $72 \mathrm{~h}$ prior to LAD occlusion; group 5, anti-IL-23+I/R (n=6) rats treated with anti-IL-23 neutralized monoclonal antibodies (200 $\mu \mathrm{g}$ per rat, i.v. into the tail vein) from Biosynthesis Biotechnology Co., Ltd. (Beijing, China) 30 min prior to LAD occlusion; group 6, Ad-IL-23+AG490+I/R $(n=6)$ rats treated with Ad-IL-23 (10 $11 \mathrm{pfu} / \mathrm{ml}, 100 \mu \mathrm{l}$ per rat, intramyocardially) for $72 \mathrm{~h}$ and injection of AG490 (an inhibitor of JAK2-STAT3) from MedChemExpress USA (Monmouth Junction, NJ, USA; $3 \mathrm{mg} / \mathrm{kg}$, i.v. into tail vein), $30 \mathrm{~min}$ prior to LAD occlusion.

Sodium pentobarbital $(2.5 \% ; 45 \mathrm{mg} / \mathrm{kg}$, i.p.) was used as the anesthetic in surgery. The I/R used in the rats model was performed, as previously described (14). Changes in ST segment elevation in Leads-II and regional cyanosis of the myocardial surface were considered to be signs of successful establishment of the myocardial I/R model. Subsequently, a half dose $(22.5 \mathrm{mg} / \mathrm{kg}$, i.p.) of $2.5 \%$ sodium pentobarbital was injected into the postoperative rats. Samples, including $2 \mathrm{ml}$ of blood from the jugular vein and heart tissue in the infarct area (white) and risk area $(5 \mathrm{~mm}$ around the infarct area) were obtained immediately and frozen at $-80^{\circ} \mathrm{C}$ for subsequent assays.

Assessment of myocardial injury. A previously described double-staining technique was used to determine the infarct size (14). In brief, following $4 \mathrm{~h}$ reperfusion, the LAD was occluded again and $2 \mathrm{ml}$ Evans Blue dye (1\%; Sigma-Aldrich; Merck Millipore, Darmstadt, Germany) was injected via the jugular vein. The heart was excised and frozen at $-80^{\circ} \mathrm{C}$ for $15 \mathrm{~min}$, and was then cut into $1.5 \mathrm{~mm}$ transverse sections from the apex to the base, which were subsequently incubated in $1.0 \%$ 2,3,5-triphenyltetrazolium chloride (TTC; Sigma-Aldrich; Merck Millipore) for $15 \mathrm{~min}$ at $37^{\circ} \mathrm{C}$. The sizes of the infarct area (white) and the area at risk (red and white) were measured using an image analyzer (Image-Pro Plus 3.0; Media Cybernetics, Inc., Silver Spring, MD, USA). The percentage of the risk area volume (\% infarct area/risk + infarct area) was used to determine the infarct size.

The serum levels of lactate dehydrogenase (LDH) and creatine kinase (CK) were measured in the blood samples, which were collected, centrifuged $\left(2,050 \mathrm{x} \mathrm{g}, 5 \mathrm{~min}, 4^{\circ} \mathrm{C}\right)$ and stored at $-20^{\circ} \mathrm{C}$ until analyses. Standard techniques using commercialized assay kits were used according to the manufacturer's protocol (Nanjing Jiancheng Bioengineering Institute, Najing, China) for the analyses. Values are expressed in international units (IU) per liter.

Assessment of myocardial inflammatory parameters. The levels of TNF- $\alpha$ and IL-6 in myocardial tissues were measured using commercial enzyme-linked immunosorbent assay kits (TNF- $\alpha$ and IL-6; Nanjing Jiancheng Bioengineering Institute) according to the manufacturer's protocol. The sensitivity of the assay was $1 \mathrm{pg} / \mathrm{ml}$.

Cardiac myocyte protein concentrations were measured using western blot assays as described previously (15). In brief, total protein content was determined using a bicinchoninic acid protein assay kit (Beyotime Institute of Biotechnology, Haimen, China) according the manufacturer's protocol. Protein extracts $(40 \mu \mathrm{g})$ of the cardiac tissues in radioimmuno-precipitation assay lysis buffer (Beyotime Institute of Biotechnology) were separated by $10 \%$ sodium dodecyl sulfate-polyacrylamide gel electrophoresis, transferred onto polyvinylidene difuoride membranes (EMD Millipore, Billerica, MA, USA) and probed with primary antibodies at $4^{\circ} \mathrm{C}$ overnight, including anti-IL-23 (cat no. bs-1193R; diluted 1:300; Beijing Bioss Biological Co., Ltd., Beijing, China), anti-IL-17A (cat no. bs-1183R; diluted 1:300; Beijing Bioss Biological Co., Ltd, Beijing, China) and $\beta$-actin (cat no. BM0627; diluted 1:500; Wuhan Boster Bioengineering Co, Ltd., Wuhan, China). Following incubation with the appropriate secondary antibodies (The horseradish peroxidase-conjugated mouse IgG (cat no. BA1051); The horseradish peroxidase-conjugated rabbit IgG (cat no. BA1054); diluted 1:50,000; Wuhan Boster Bioengineering Co, Ltd.) for $2 \mathrm{~h}$ at room temperature, the specific bands were visualized using an ECL detection system according to the manufacturer's protocol. 
Assessment of myocardial apoptosis. Myocardial apoptosis was examined using the TdTmediated dUTP nick-end labeling (TUNEL) assay, as described previously (16). In brief, following being fixed in $4 \%$ paraformaldehyde and embedded in paraffin, the myocardial tissue samples were cut into $5 \mu \mathrm{m}$ blocks. The percentages of apoptotic cells were evaluated in the five slides of each block using the TUNEL assay. Subsequently, five fields (magnification, $\mathrm{x} 200$ ) were randomly selected on each section under a light microscope (Leica Microsystems, Inc., Buffalo Grove, IL, USA). Cells (positive brown cells and normal blue cells) were counted using the MIAS 4.0 medical image analysis system (Beijing Bingyang Keji Corporation, Beijing, China). The apoptosis index (positive cells/total cells x 100\%) was used to express myocardial apoptosis.

The levels of B-cell lymphoma 2 (Bcl-2), Bcl-2-associated X protein (Bax) and caspase-3 in myocardial tissues were assessed using western blot assays, as mentioned above. Anti-Bcl-2 ((cat no. sc-7382; diluted 1:1,000; Santa Cruz Biotechnology, Inc., Dallas, TX, USA), anti-Bax (cat no. BS6420; diluted 1:1,000; Bioworld Technology, Minneapolis, MN, USA) and anti-caspase-3 (cat no. 19677-1-AP; diluted 1:1,000; Wuhan Mitaka Biotechnology Co, Ltd., Wuhan, China) were used as primary antibodies $\left(4^{\circ} \mathrm{C}\right.$, overnight), and the secondary antibodies were as described above (cat no. BA1051; cat no. BA1054).

Assessment of JAK2-STAT3 signaling pathway activation. The levels of JAK2, phosphorylated (P-)JAK2, STAT3 and P-STAT3 were assessed using western blot assays, as mentioned above. Anti-JAK2 (cat no. sc-21870; diluted 1:1,000; Santa Cruz Biotechnology, Inc.), anti-P-JAK2 (cat no. bs-3206R; diluted 1:200; Beijing Bioss Biological Co., Ltd.), anti-STAT3 (cat no. sc-483; diluted 1:500; Santa Cruz Biotechnology, Inc.) and anti-P-STAT3 (cat no. BS4181; diluted 1:800; Bioworld Technology) were used as primary antibodies $\left(4^{\circ} \mathrm{C}\right.$, overnight $)$. And the secondary antibodies were the horseradish peroxidase-conjugated mouse IgG (cat no. BA1051), the horseradish peroxidase-conjugated rabbit IgG (cat no. BA1054) and the horseradish peroxidase-conjugated goat IgG (cat no. BA1060); diluted 1:50,000; Wuhan Boster Bioengineering Co, Ltd..

Statistical analysis. Statistical analysis was performed using SPSS 17.0 (SPSS, Inc., Chicago, IL, USA). All values are expressed as the mean \pm standard deviation. Student's t-test was used for between-group comparisons. One-way analysis of variance or a Welch test was used for comparisons among groups, and Tukey's post hoc test was used for multiple comparisons. $\mathrm{P}<0.05$ was considered to indicate a statistically significant difference.

\section{Results}

Myocardial expression of IL-23 during myocardial $I / R$. Compared with the $\mathrm{SO}$ group, the I/R group had a significantly higher expression level of IL-23 (0.578 \pm 0.018 , vs. 0.163 \pm 0.018 ; $\mathrm{P}<0.05)$. The level of IL-23 in the Ad-IL-23 group was significantly increased, compared with that in the I/R group $(0.935 \pm 0.038 ; \mathrm{P}<0.05)$. However, no significant difference was found between the Ad-GFP group and I/R group $(0.659 \pm 0.013$; P>0.05; Fig. 1).

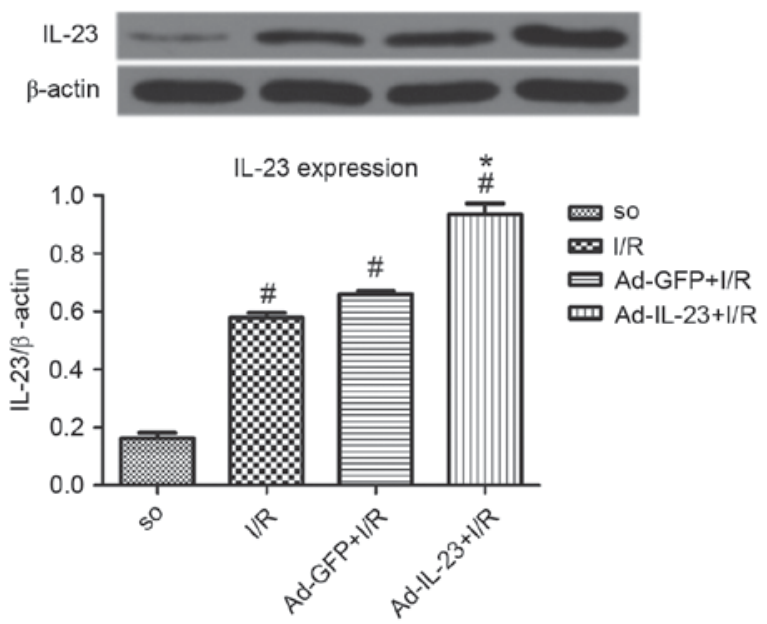

Figure 1. I/R increases the expression level of IL-23 in myocardial tissue, which is further increased by AD-IL-23. I/R increased levels of IL-23, and Ad-IL-23 further enhanced the high level of IL-23 induced by myocardial

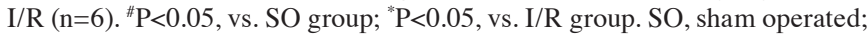
$\mathrm{I} / \mathrm{R}$, ischemia/reperfusion; IL-23, interleukin 23; Ad, adenovirus.
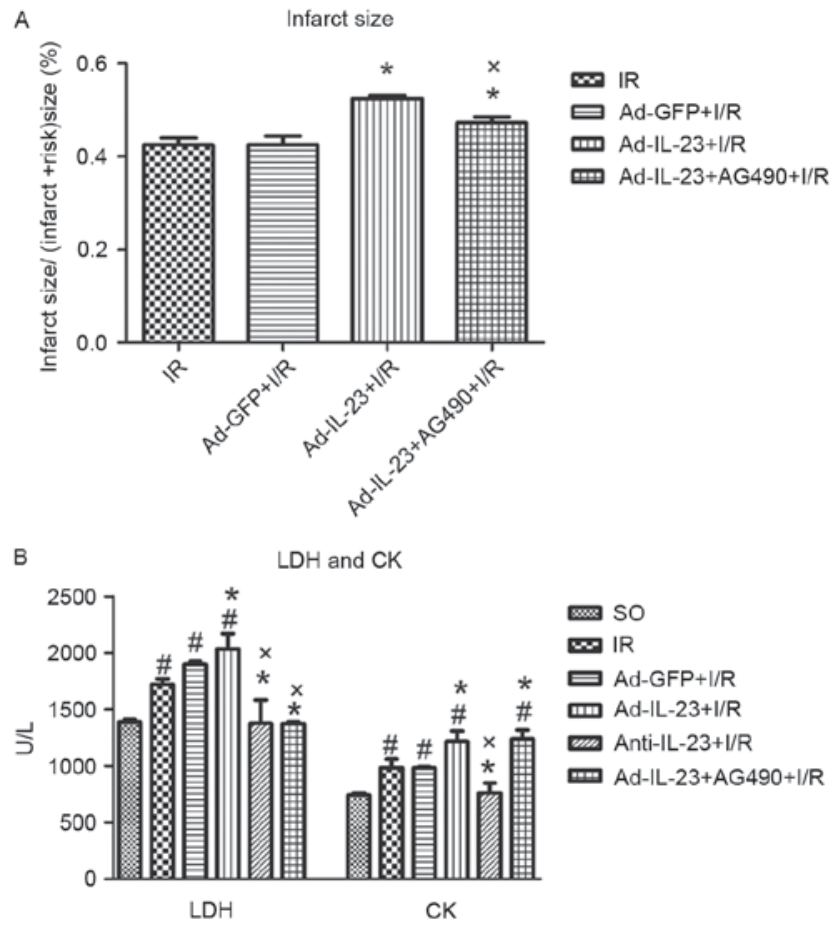

Figure 2. Ad-IL-23 increases I/R-induced myocardial injury, which is partially attenuated by AG490. (A) Myocardial infarct size ( $n=5)$. (B) Serum levels of $\mathrm{LDH}$ and $\mathrm{CK}(\mathrm{n}=6) .{ }^{*} \mathrm{P}<0.05$, vs. SO group; ${ }^{*} \mathrm{P}<0.05$, vs. I/R group; ${ }^{x} \mathrm{P}<0.05$, vs. Ad-IL-23+I/R group. SO, sham operated; I/R, ischemia/reperfusion; IL-23, interleukin 23; Ad, adenovirus; LDH, lactate dehydrogenase; CK, creatine kinase.

IL-23 promotes myocardial injury following I/R. Compared with the I/R group, the infarct size in the Ad-IL-23 group was significantly increased $(52.4 \pm 0.7$, vs. $42.4 \pm 1.5 \%$; $\mathrm{P}<0.05)$. However, no significant difference was found between the Ad-GFP group and I/R group $(42.5 \pm 1.9 \%$; $\mathrm{P}>0.05)$. The addition of AG490 significantly inhibited the effect of Ad-IL-23 with regard to decreasing infarct size, compared with that in the Ad-IL-23 group (47.2 $\pm 1.3 \%$; $\mathrm{P}<0.05$; Fig. 2A). 

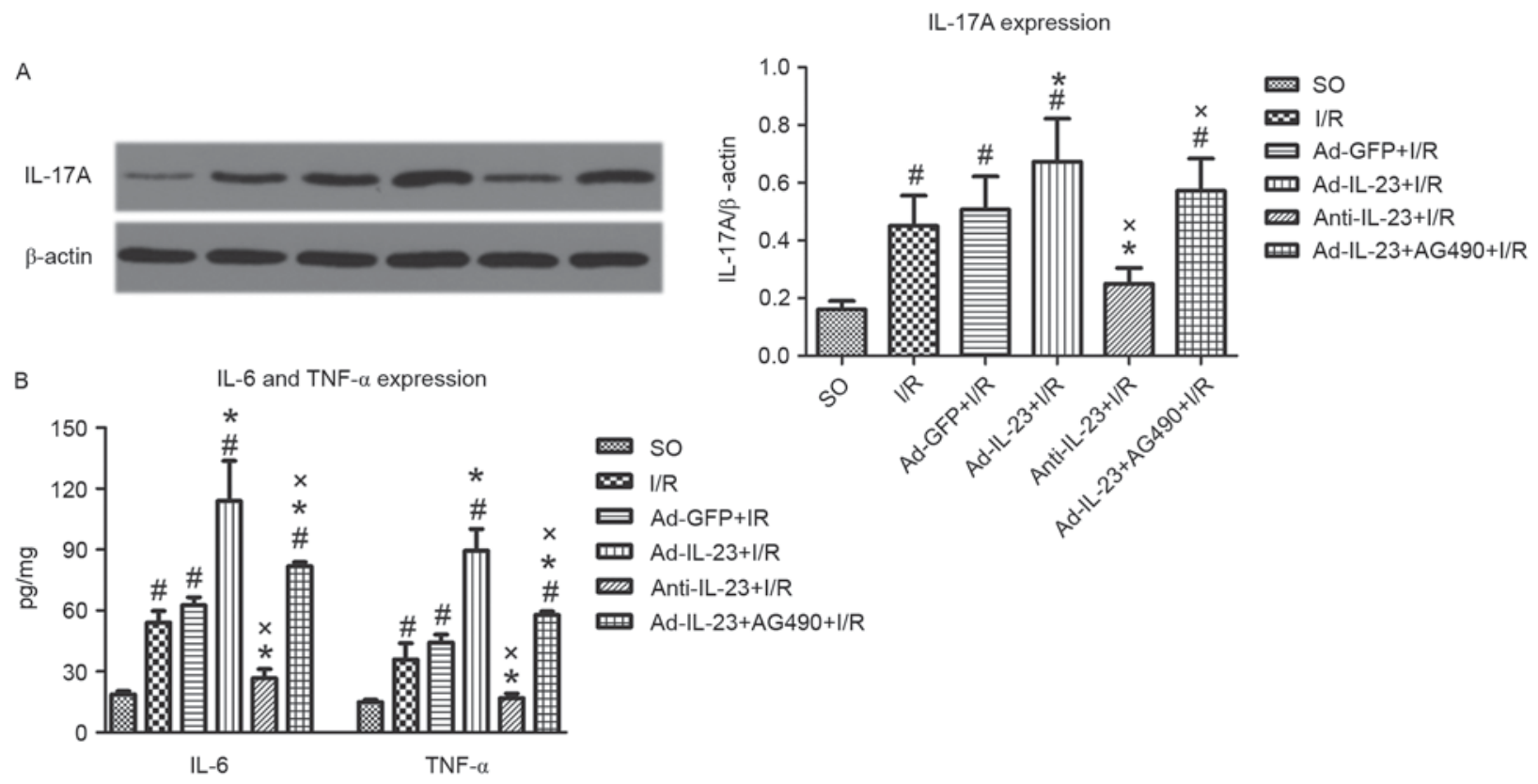

Figure 3. Ad-IL-23 intensifies the high expression levels of IL-17A, TNF- $\alpha$ and IL-6 induced by myocardial I/R, which is inhibited by AG490. (A) Levels of IL-17A in myocardial tissues from infarct and risk regions (n=6). (B) Expression levels of TNF- $\alpha$ and IL-6 in myocardial tissues from infarct and risk regions $(\mathrm{n}=6) .{ }^{*} \mathrm{P}<0.05$, vs. SO group; ${ }^{*} \mathrm{P}<0.05$, vs. I/R group; ${ }^{\times} \mathrm{P}<0.05$, vs. Ad-IL-23+I/R group. SO, sham operated; I/R, ischemia/reperfusion; IL, interleukin; Ad, adenovirus; TNF- $\alpha$, tumor necrosis factor- $\alpha$.

Following $4 \mathrm{~h}$ reperfusion, the levels of $\mathrm{LDH}$ $(1,721.2 \pm 106.1 \mathrm{U} / 1)$ and $\mathrm{CK}(985.2 \pm 172.3 \mathrm{U} / \mathrm{l})$ in the $\mathrm{I} / \mathrm{R}$ group were significantly increased $(\mathrm{P}<0.05)$, compared with that in the SO group. However, no significant difference was found between the Ad-GFP group and I/R group in LDH $(1,899.0 \pm 44.0 \mathrm{U} / 1)$ or CK $(981.5 \pm 17.1 \mathrm{U} / 1 ; \mathrm{P}>0.05)$. Ad-IL-23 increased the high expression levels of $\mathrm{LDH}(2,035.4 \pm 270.4 \mathrm{U} / \mathrm{l})$ and CK $(1215.7 \pm 187.5 \mathrm{U} / \mathrm{l})$ induced by myocardial $\mathrm{I} / \mathrm{R}(\mathrm{P}<0.05)$ compared with the I/R group. However, the levels of LDH $(1,376.6 \pm 411.1 \mathrm{U} / \mathrm{l})$ and CK $(762.2 \pm 175.5 \mathrm{U} / \mathrm{l})$ in the anti-IL-23 group were decreased, compared with those in the I/R group $(\mathrm{P}<0.05)$. Furthermore, the addition of AG490 partially inhibited the effect of Ad-IL-23 with regard to decreasing the expression level of $\mathrm{LDH}(1,374.1 \pm 27.3 \mathrm{U} / \mathrm{l})$ compared with that in the Ad-IL-23 group ( $\mathrm{P}<0.05$; Fig. $2 \mathrm{~B})$.

IL-23 intensifies inflammatory responses. Compared with the SO group, a higher expression level of IL-17A was observe in the I/R group $(0.451 \pm 0.105$, vs. $0.160 \pm 0.030 ; \mathrm{P}<0.05)$. Ad-IL-23 enhanced the increased expression of IL-17A induced by myocardial I/R $(0.673 \pm 0.149 ; \mathrm{P}<0.05)$. However, anti-IL-23 significantly inhibited the I/R-induced increase of IL-17A $(0.250 \pm 0.055 ; \mathrm{P}<0.05)$. Furthermore, the addition of AG490 significantly inhibited the effect of Ad-IL-23 (0.572 \pm 0.112 ; $\mathrm{P}<0.05$; Fig. 3A.

Following $4 \mathrm{~h}$ reperfusion, the levels of TNF- $\alpha$ $(35.9 \pm 14.0 \mathrm{pg} / \mathrm{mg})$ and IL-6 $(54.1 \pm 9.8 \mathrm{pg} / \mathrm{mg})$ were significantly increased $(\mathrm{P}<0.05)$, compared with those in the SO group. Ad-IL-23 increased the high expression levels of TNF- $\alpha$ $(89.5 \pm 18.5 \mathrm{pg} / \mathrm{mg})$ and IL-6 $(113.9 \pm 34.3 \mathrm{pg} / \mathrm{mg})$ induced by myocardial $\mathrm{I} / \mathrm{R}(\mathrm{P}<0.05)$. However, anti-IL-23 decreased the expression levels of TNF- $\alpha(17.0 \pm 3.8 \mathrm{pg} / \mathrm{mg})$ and IL-6 $(26.7 \pm 7.8 \mathrm{pg} / \mathrm{mg}$ ), compared with those in the I/R group $(\mathrm{P}<0.05)$. Furthermore, the addition of AG490 significantly inhibited the effect of Ad-IL-23 with regard to decreasing the expression levels of TNF- $\alpha(57.8 \pm 3.0 \mathrm{pg} / \mathrm{mg})$ and IL-6 $(81.9 \pm 3.4 \mathrm{pg} / \mathrm{mg})$, compared with those in Ad-IL-23 group $(\mathrm{P}<0.05$; Fig. 3B.

IL-23 accelerates myocardial apoptosis. Ad-IL-23 significantly increased the I/R-induced myocardial apoptosis $(26.6 \pm 1.0$, vs. $18.7 \pm 0.5 \%$; $\mathrm{P}<0.05)$, however, its effect was inhibited by AG490 (21.9 $\pm 1.1 \%$; P<0.05; Fig. 4A.

Following $4 \mathrm{~h}$ reperfusion, the levels of total caspase- 3 $(0.306 \pm 0.062)$ and cleaved caspase- $3(0.303 \pm 0.006)$ were significantly increased $(\mathrm{P}<0.05)$, compared with those in the SO group. Ad-IL-23 significantly increased the high expression levels of total caspase-3 $(0.562 \pm 0.033)$ and cleaved caspase-3 $(0.530 \pm 0.055)$ induced by myocardial $\mathrm{I} / \mathrm{R}(\mathrm{P}<0.05)$. However, anti-IL-23 decreased the I/R-induced high level of cleaved caspase- $3(0.171 \pm 0.026, \mathrm{P}<0.05)$ but not total caspase-3 $(0.312 \pm 0.049 ; \mathrm{P}>0.05)$. The effects of Ad-IL-23 on total caspase-3 $(0.426 \pm 0.041)$ and cleaved caspase-3 $(0.352 \pm 0.022)$ were inhibited by AG490 (P<0.05; Fig. 4B.

Compared with the SO group, the I/R group had a lower ratio of $\mathrm{Bcl}-2$ to $\mathrm{Bax}(1.03 \pm 0.11$, vs. $2.74 \pm 0.64 ; \mathrm{P}<0.05)$. However, the ratio was even lower in the Ad-IL-23 group $(0.27 \pm 0.08 ; \mathrm{P}<0.05)$, and the addition of AG490 significantly inhibited the effect of Ad-IL-23 $(0.79 \pm 0.01 ; \mathrm{P}<0.05)$. The ratio of Bcl-2 to Bax in the anti-IL-23 group was significantly higher, compared with that in the I/R group $(1.62 \pm 0.17 ; \mathrm{P}<0.05$; Fig. 4C. The expression levels of Bcl-2 showed the same trend, whereas the expression of Bax showed an opposite trend to that of Bcl-2 (Fig. 4D).

IL-23 regulates the JAK2-STAT3 signaling pathway. Compared with the I/R group, the Ad-IL-23 group had significantly higher $(\mathrm{P}<0.05)$ expression levels of P-JAK2 
A
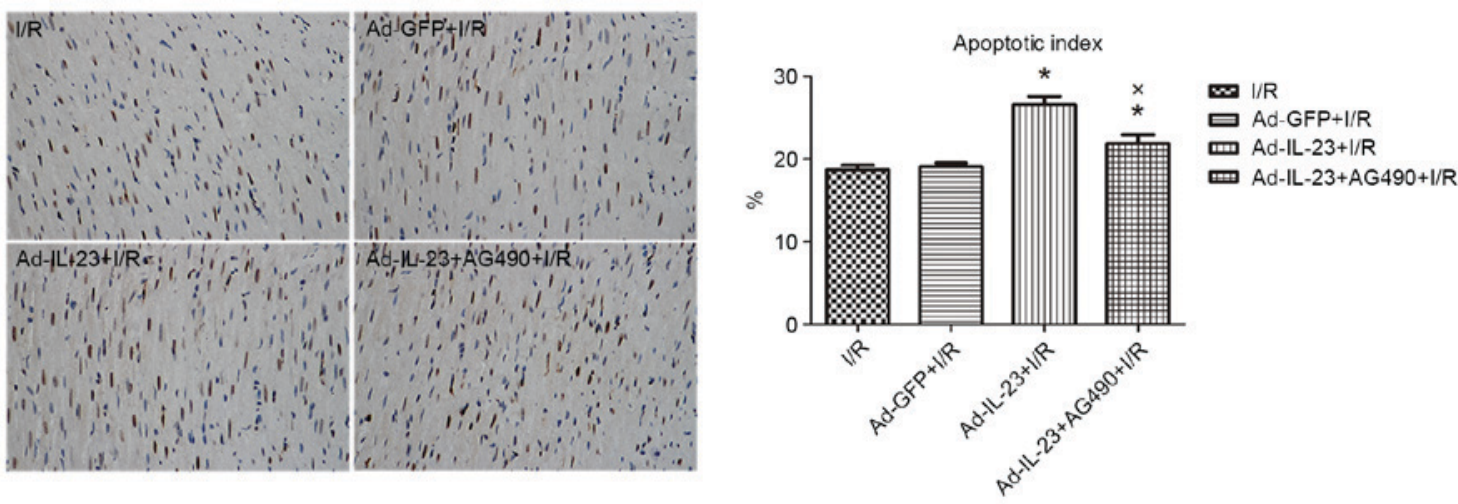

B
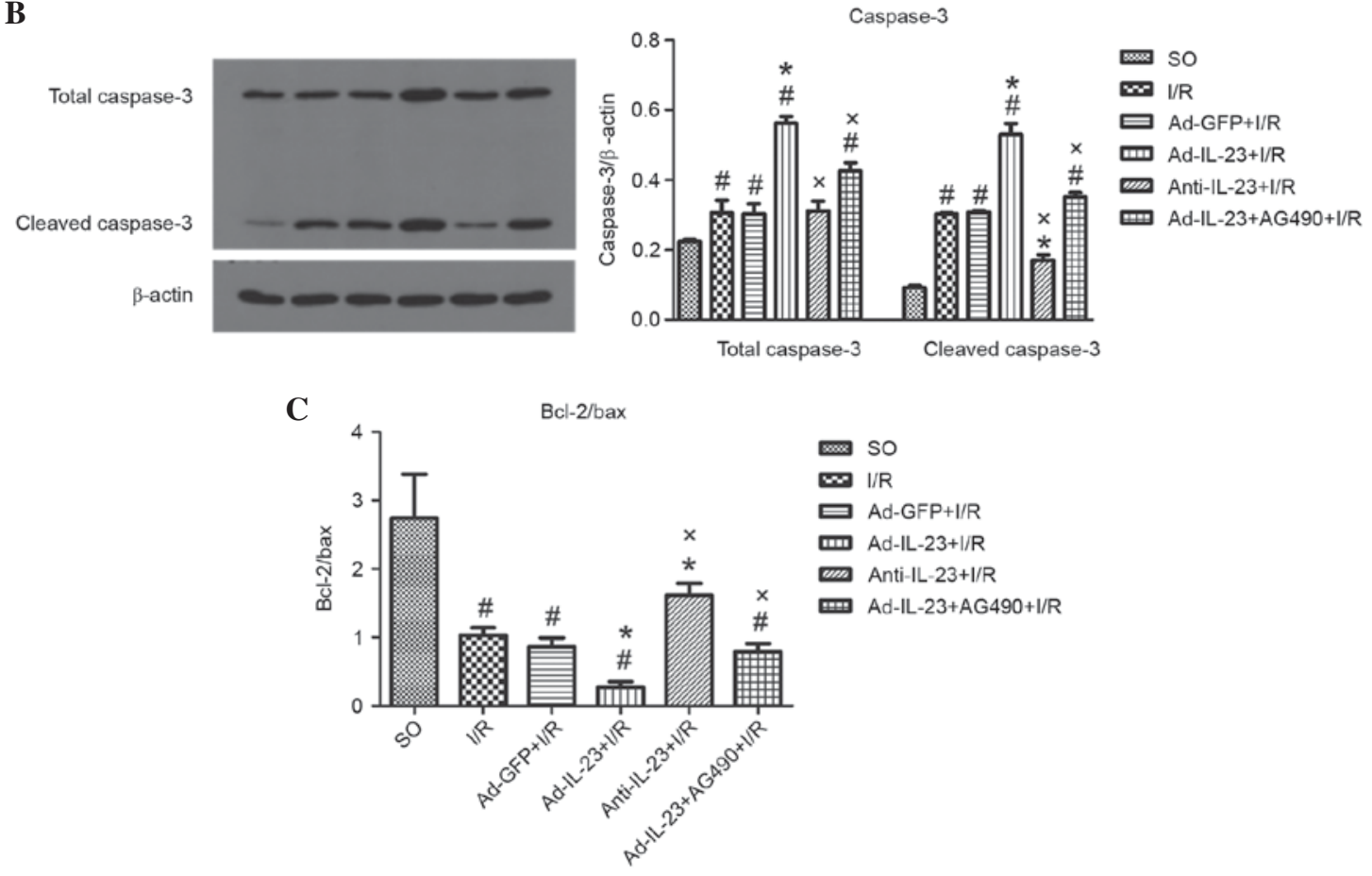

D
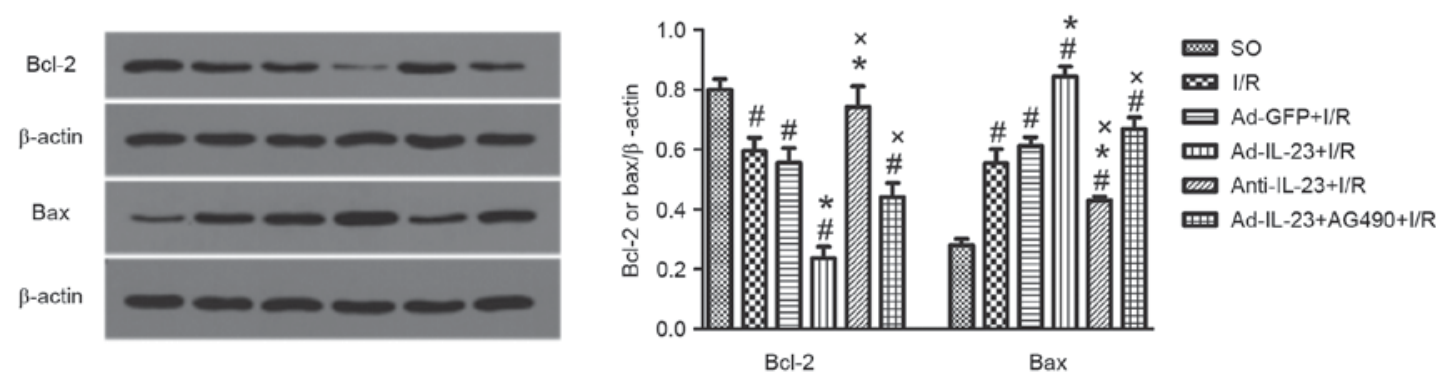

Figure 4. Ad-IL-23 increases I/R-induced myocardial apoptosis, which is partially inhibited by AG490. (A) Images and apoptotic indices (magnification, $\mathrm{x} 200$ ) of myocardial tissues from infarct regions $(\mathrm{n}=5$ ). (B) Expression levels of total caspase- 3 and cleaved caspase-3 in myocardial tissues from infarct and risk regions ( $\mathrm{n}=6$ ). (C) Ratio of Bcl-2 to Bax in myocardial tissues from infarct and risk regions (n 6). (D) Levels of Bcl-2 and Bax in myocardial tissues from infarct and risk regions $(\mathrm{n}=6) .{ }^{~} \mathrm{P}<0.05$, vs. SO group; ${ }^{*} \mathrm{P}<0.05$, vs. I/R group; ${ }^{x} \mathrm{P}<0.05$, vs. Ad-IL-23+I/R group. SO, sham operated; $\mathrm{I} / \mathrm{R}$, ischemia/reperfusion; IL-23, interleukin-23; Ad, adenovirus; Bcl-2, B-cell lymphoma-2; Bax, Bcl-2-associated X protein.

$(1.033 \pm 0.092$, vs. $0.695 \pm 0.036)$ and P-STAT3 $(0.968 \pm 0.063$, vs. $0.687 \pm 0.033)$, however, this not the case with total JAK2 $(0.948 \pm 0.074$, vs. $0.963 \pm 0.074)$ or STAT3 $(0.823 \pm 0.086$, vs $0.800 \pm 0.061 ; \mathrm{P}>0.05)$. The levels of P-JAK2 and P-STAT3 in the anti-IL-23 group were significantly lower, compared with those in the $\mathrm{I} / \mathrm{R}$ group $(0.426 \pm 0.023$ and $0.383 \pm 0.066$, respectively; $\mathrm{P}<0.05$; Fig. $5 \mathrm{~A}$ and $\mathrm{B}$ ).

\section{Discussion}

Myocardial inflammation is one of the crucial pathophysiological processes in myocardial I/R injury, which can be promoted by the release of various cytokines. The inflammatory responses ultimately aggravate tissue injury (17). Previous studies have demonstrated that the components of adaptive 
A

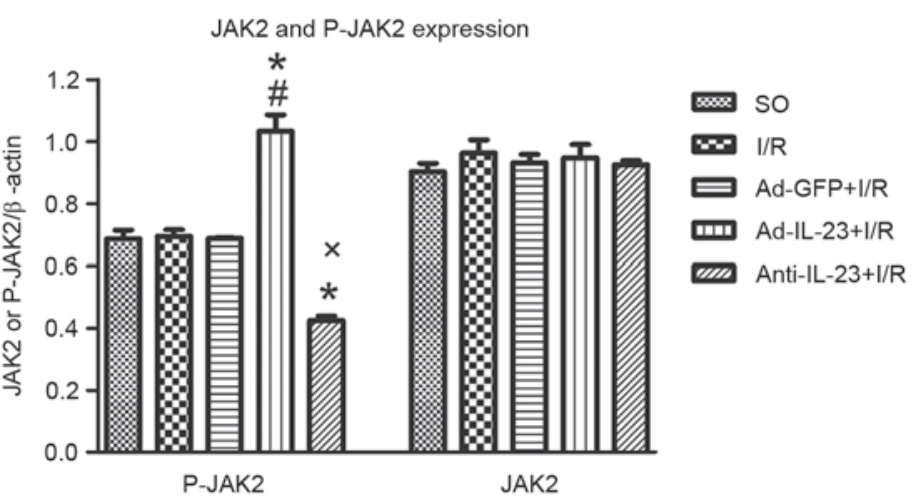

B

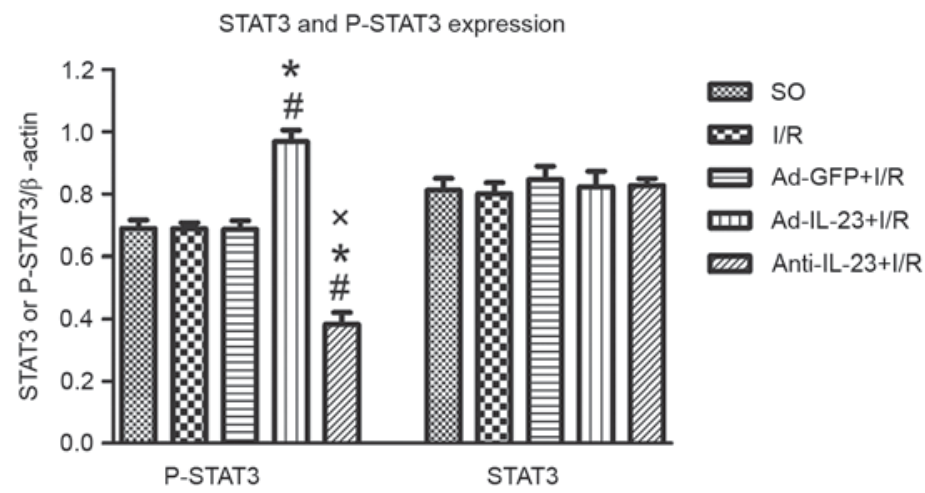

Figure 5. Ad-IL-23 activates the JAK2-STAT3 signaling pathway. (A) Ad-IL-23 increased the expression level of P-JAK2, but not total JAK2 in myocardial tissues in infarct and risk regions ( $\mathrm{n}=6$ ). (B) Ad-IL-23 increased the expression level of P-STAT3, but not total STAT3, in myocardial tissues from infarct and risk regions $(\mathrm{n}=6) .{ }^{\prime} \mathrm{P}<0.05$, vs. SO group; ${ }^{*} \mathrm{P}<0.05$, vs. I/R group; ${ }^{\mathrm{X}} \mathrm{P}<0.05$, vs. Ad-IL-23+I/R group. SO, sham operated; I/R, ischemia/reperfusion; IL-23, interleukin-23; Ad, adenovirus; JAK2, Janus kinase 2; P-JAK2, phosphorylated JAK2; STAT3, signal transducer and activator of transcription 3; P-STAT3, phosphorylated STAT3.

immunity and innate immunity are involved in myocardial I/R injury (18). The heterodimeric cytokine IL-23, primarily secreted by activated dendritic cells and macrophages, functions as a link between innate and adaptive immunity by promoting the proliferation of immune cells and secretion of cytokines (19).

In the present study, it was found that $\mathrm{I} / \mathrm{R}$ significantly increased the expression of IL-23 in myocardial tissues, which was consistent with the findings of previous studies, indicating that macrophages can rapidly respond to endogenous stimulating factors following tissue injury and have a pathogenic role through their secretion of pro-inflammatory factors $(20,21)$.

In the present study, it was found that IL-23 promoted inflammatory responses via increasing the expression levels of TNF- $\alpha$ and IL- 6 in myocardial I/R. Previous studies have demonstrated that IL-23 is important in several inflammatory diseases, including myocardial I/R injury (8-11). Once released from activated dendritic cells and macrophages, IL-23 functions as a pro-inflammatory stimulus, which induces the differentiation of naive lymphocytes, including $\mathrm{CD} 4^{+} \mathrm{T}$ cells, and the secretion of inflammatory cytokines, including IL-1 $\beta$, IFN- $\gamma$, TNF- $\alpha$ and IL-6 $(8,22-24)$, indicating that IL-23 may reinforce the inflammatory process and intensify myocardial I/R injury through this mechanism.

The present study also found that the upregulation of IL-23 significantly increased the expression level of IL-17A. As an early pro-inflammatory cytokine, IL-17A is crucial in myocardial I/R injury $(12,25)$. Previous studies have suggested that, in addition to directly aggravating myocardial I/R injury, IL-17A stimulates endothelial cells and macrophages, and increases the secretion of pro-inflammatory cytokines, including IL-1, IL-6, TNF- $\alpha$ and c-reactive protein, which further reinforces the inflammatory response and myocardial I/R injury (12). In addition, IL-17A can regulate the expression of granulocyte colony stimulating factor and chemokines, including CXC motif chemokine ligand (CXCL)1, CXCL5 and IL-18, to amplify and collect neutrophils, which may be another mechanism promoting myocardial inflammation and injury (12). Li et al (25) demonstrated that the expression of IL-17A was increased in myocardial I/R, and that the inhibition of IL-17A with anti-IL-17A significantly reduced levels of cardiac troponin $\mathrm{T}$ and myocardial infarct size, ameliorateing myocardial I/R injury. These results suggested that IL-23 may promote inflammatory responses and myocardial I/R injury by accelerating the secretion of IL-17A. Previous studies have demonstrated that the generation of IL-17A induced by IL-23 is mediated by activation of the JAK2, phosphoinositide 3-kinase/AKT, nuclear factor- $\mathrm{KB}$ and STAT3 signaling pathways (26-29), which may also be pathways through which IL-23 regulates the expression of IL-17A in myocardial I/R, although the precise mechanism remains to be elucidated.

Apoptosis is another important pathophysiological process during myocardial $\mathrm{I} / \mathrm{R}$, and a previous study found that the inhibition of apoptosis protected the heart from I/R injury (30). The present study found that IL-23 significantly reduced the ratio of Bcl-2 to Bax and increased the apoptotic index, indicating that IL-23 accelerated myocardial apoptosis during I/R injury. Liao et al (12) suggested that the upregulation 
(exogenous IL-17A treatment) or downregulation (anti-IL-17A monoclonal antibody treatment or IL-17A-knockout) of IL-17A markedly affected the severity of I/R injury through mediating cardiomyocyte apoptosis and neutrophil infiltration. Another study (11) reported that IL-17A, as a downstream pro-inflammatory cytokine, can regulate cardiomyocyte apoptosis. Therefore, it was hypothesized that IL-23 aggravates cardiomyocyte apoptosis by regulating the release of IL-17A. In the present study, it was demonstrated that IL-23 had a promoting effect in myocardial I/R injury via regulation of the expression of IL-17A, which is an novel finding, although previous studies have demonstrated that the IL-23/IL-17A axis is important in several inflammatory diseases and I/R in other organs $(25,31,32)$.

In the present study, it was found that IL-23 activated the JAK2-STAT3 signaling pathway, and inhibiting this pathway suppressed the pro-inflammatory and pro-apoptotic effects of IL-23. The JAK2-STAT3 signaling pathway is a primary downstream signaling pathway of IL-23, which is an important signaling pathway in various cardiovascular diseases, including myocardial I/R injury (33-35). Previous studies have demonstrated that, once activated by IL-23, the JAK2-STAT3 pathway induces the activation and differentiation of memory $\mathrm{T}$ cells, including $\mathrm{CD} 4^{+} \mathrm{T}$ cells, into IL-17A secretory cells (Th17/Thil-17) and upregulates the secretion of IL-17A (36). In addition to IL-17A, activated memory $\mathrm{T}$ cells can secrete a mass of pro-inflammatory factors, including IL- 6 and TNF- $\alpha$, which are also crucial cytokines in the inflammatory process of myocardial I/R injury (22-25). The promoting effects of IL-17A in myocardial I/R injury suggested that the JAK2-STAT3 signaling pathway may be involved in IL-17A release and the promoting effects of IL-23 in myocardial I/R injury.

In conclusion, the present study suggested that IL-23 promoted myocardial I/R injury by increasing inflammatory responses and myocardial apoptosis, which may be associated with high expression levels of IL-17A and upregulation of the JAK2-STAT3 signaling pathway.

\section{Acknowledgements}

This study was supported by grants from the National Natural Science Foundation of China (grant nos. 81500274 and 81370308) and the Natural Science Foundation of Hubei Province (grant no. 2015CFB207).

\section{References}

1. Yellon DM and Hausenloy DJ: Myocardial reperfusion injury. N Engl J Med 357: 1121-1135, 2007.

2. Andrassy M, Volz HC, Igwe JC, Funke B, Eichberger SN Kaya Z, Buss S, Autschbach F, Pleger ST, Lukic IK, et al: High-mobility group box-1 in ischemia-reperfusion injury of the heart. Circulation 117: 3216-3226, 2008.

3. Xiong J, Xue FS, Yuan YJ, Wang Q, Liao X and Wang WL: Cholinergic anti-inflammatory pathway: A possible approach to protect against myocardial ischemia reperfusion injury. Chin Med J (Engl) 123: 2720-2726, 2010.

4. Yang M, Chen J, Zhao J and Meng M: Etanercept attenuates myocardial ischemia/reperfusion injury by decreasing inflammation and oxidative stress. PLoS One 9: e108024, 2014.

5. Frangogiannis NG, Smith CW and Entman ML: The inflammatory response in myocardial infarction. Cardiovasc Res 53: 31-47, 2002.
6. Oppmann B, Lesley R, Blom B, Timans JC, Xu Y, Hunte B, Vega F, Yu N, Wang J, Singh K, et al: Novel p19 protein engages IL-12p40 to form a cytokine, IL-23, with biological activities similar as well as distinct from IL-12. Immunity 13: 715-725, 2000.

7. Yannam GR, Gutti T and Poluektova LY: IL-23 in infections, inflammation, autoimmunity and cancer: Possible role in HIV-1 and AIDS. J Neuroimmune Pharmacol 7: 95-112, 2012.

8. Langrish CL, Chen Y, Blumenschein WM, Mattson J, Basham B Sedgwick JD, McClanahan T, Kastelein RA and Cua DJ: IL-23 drives a pathogenic $\mathrm{T}$ cell population that induces autoimmune inflammation. J Exp Med 201: 233-240, 2005.

9. Morrison PJ, Ballantyne SJ and Kullberg MC: Interleukin-23 and $\mathrm{T}$ helper 17-type responses in intestinal inflammation: From cytokines to T-cell plasticity. Immunology 133: 397-408, 2011.

10. Yao J, Liu L and Yang M: Interleukin-23 receptor genetic variants contribute to susceptibility of multiple cancers. Gene 533: 21-25, 2014

11. Zhu H, Li J, Wang S, Liu K, Wang L and Huang L: Hmgb1-TLR4-IL-23-IL-17A axis promote ischemia-reperfusion injury in a cardiac transplantation model. Transplantation 95: 1448-1454, 2013

12. Liao YH, Xia N, Zhou SF, Tang TT, Yan XX, Lv BJ, Nie SF, Wang J, Iwakura Y, Xiao H, et al: Interleukin-17A contributes to myocardial ischemia/reperfusion injury by regulating cardiomyocyte apoptosis and neutrophil infiltration. J Am Coll Cardiol 59: 420-429, 2012.

13. Research NRCU: Guide for the care and use of laboratory animals. National academies press (US), Washington (DC), 1996.

14. Hu X, Cui B, Zhou X, Xu C, Lu Z and Jiang H: Ethyl pyruvate reduces myocardial ischemia and reperfusion injury by inhibiting high mobility group box 1 protein in rats. Mol Biol Rep 39: 227-231, 2012.

15. Xu H, Su Z, Wu J, Yang M, Penninger JM, Martin CM, Kvietys PR and Rui T: The alarmin cytokine, high mobility group box 1, is produced by viable cardiomyocytes and mediates the lipopolysaccharide-induced myocardial dysfunction via a TLR4/phosphatidylinositol 3-kinase gamma pathway. J Immunol 184: 1492-1498, 2010.

16. Ni J, Hu G, Xiong J, Shen J, Shen J, Yang L, Tang M, Zhao Y, Ying G, Yu G, et al: Involvement of interleukin-17A in pancreatic damage in rat experimental acute necrotizing pancreatitis. Inflammation 36: 53-65, 2013.

17. Steffens S, Montecucco F and Mach F: The inflammatory response as a target to reduce myocardial ischaemia and reperfusion injury. Thromb Haemost 102: 240-247, 2009.

18. Linfert D, Chowdhry $\mathrm{T}$ and Rabb H: Lymphocytes and ischemia-reperfusion injury. Transplant Rev (Orlando) 23: 1-10, 2009.

19. Sun J, Walsh M, Villarino AV, Cervi L, Hunter CA, Choi Y and Pearce EJ: TLR ligands can activate dendritic cells to provide a MyD88-dependent negative signal for Th2 cell development. J Immunol 174: 742-751, 2005.

20. Mosser DM and Edwards JP: Exploring the full spectrum of macrophage activation. Nat Rev Immunol 8: 958-969, 2008.

21. Wang X, Sun R, Wei H and Tian Z: High-mobility group box 1 (HMGB1)-Toll-like receptor (TLR)4-interleukin (IL)-23-IL-17A axis in drug-induced damage-associated lethal hepatitis: Interaction of $\gamma \delta \mathrm{T}$ cells with macrophages. Hepatology 57: 373-384, 2013.

22. McAllister F, Henry A, Kreindler JL, Dubin PJ, Ulrich L, Steele C, Finder JD, Pilewski JM, Carreno BM, Goldman SJ, et al: Role of IL-17A,IL-17F, and the IL-17 receptor in regulating growth-related oncogene-alpha and granulocyte colony-stimulating factor in bronchial epithelium: Implications for airway inflammation in cystic fibrosis. J Immunol 175: 404-412, 2005.

23. Stark MA, Huo Y, Burcin TL, Morris MA, Olson TS and Ley K: Phagocytosis of apoptotic neutrophils regulates granulopoiesis via IL-23 and IL-17. Immunity 22: 285-294, 2005.

24. Vanden ES, Goriely S, De Wit D, Willems F and Goldman M: IL-23 up-regulates IL-10 and induces IL-17 synthesis by polyclonally activated naive T cells in human. Eur J Immunol 35: 469-475, 2005.

25. Li L, Huang L, Vergis AL, Ye H, Bajwa A, Narayan V, Strieter RM, Rosin DL and Okusa MD: IL-17 produced by neutrophils regulates IFN-gamma-mediated neutrophil migration in mouse kidney ischemia-reperfusion injury. J Clin Invest 120: 331-342, 2010. 
26. Cho ML, Kang JW, Moon YM, Nam HJ, Jhun JY, Heo SB Jin HT, Min SY, Ju JH, Park KS, et al: STAT3 and NF-kappaB signal pathway is required for IL-23-mediated IL-17 production in spontaneous arthritis animal model IL-1 receptor antagonist-deficient mice. J Immunol 176: 5652-5661, 2006.

27. Herndon TM, Pirone DM, Tsokos GC and Chen CS: $\mathrm{T}$ cell-to-T cell clustering enhances NF-kappaB activity by a PI3K signal mediated by Cbl-b and Rho. Biochem Biophys Res Commun 332: 1133-1139, 2005.

28. Hunter CA: New IL-12-family members: IL-23 and IL-27, cytokines with divergent functions. Nat Rev Immunol 5: 521-531, 2005.

29. Kim KW, Cho ML, Park MK, Yoon CH, Park SH, Lee SH and Kim HY: Increased interleukin-17 production via a phosphoinositide 3-kinase/Akt and nuclear factor kappaB-dependent pathway in patients with rheumatoid arthritis. Arthritis Res Ther 7: R139-R148, 2005.

30. Xie L, Pi X, Wang Z, He J, Willis MS and Patterson C: Depletion of PHD3 protects heart from ischemia/reperfusion injury by inhibiting cardiomyocyte apoptosis. J Mol Cell Cardiol 80: $156-165,2015$.

31. Hillyer P, Larché MJ, Bowman EP, McClanahan TK, de Waal Malefyt R, Schewitz LP, Giddins G, Feldmann M, Kastelein RA and Brennan FM: Investigating the role of the interleukin-23/-17A axis in rheumatoid arthritis. Rheumatology (Oxford) 48: $1581-1589,2009$.
32. Shichita T, Sugiyama Y, Ooboshi H, Sugimori H, Nakagawa R, Takada I, Iwaki T, Okada Y, Iida M, Cua DJ, et al: Pivotal role of cerebral interleukin-17-producing gammadeltaT cells in the delayed phase of ischemic brain injury. Nat Med 15: 946-950, 2009.

33. Boengler K, Hilfiker-Kleiner D, Drexler H, Heusch G and Schulz R: The myocardial JAK/STAT pathway: From protection to failure. Pharmacol Ther 120: 172-185, 2008

34. Knight RA, Scarabelli TM and Stephanou A: STAT transcription in the ischemic heart. Jakstat 1: 111-117, 2012.

35. Jacoby JJ, Kalinowski A, Liu MG, Zhang SS, Gao Q, Chai GX, Ji L, Iwamoto Y, Li E, Schneider M, et al: Cardiomyocyte-restricted knockout of STAT3 results in higher sensitivity to inflammation, cardiac fibrosis, and heart failure with advanced age. Proc Natl Acad Sci USA 100: 12929-12934, 2003.

36. Mathur AN, Chang HC, Zisoulis DG, Stritesky GL, Yu Q, O'Malley JT, Kapur R, Levy DE, Kansas GS and Kaplan MH: Stat 3 and Stat 4 direct development of IL-17-secreting Th cells. J Immunol 178: 4901-4907, 2007. 